Durodola, J. (2017) 'Functionally graded adhesive joints - a review and prospects', International Journal of Adhesion and Adhesives

DOI: https://doi.org/10.1016/j.ijadhadh.2017.02.008

This document is the authors' Accepted Manuscript.

License: https://creativecommons.org/licenses/by-nc-nd/4.0

Available from RADAR: https://radar.brookes.ac.uk/radar/items/48e4b641-315a-47a5-817a-e204c10f1afd/1/

Copyright (C) and Moral Rights are retained by the author(s) and/ or other copyright owners unless otherwise waved in a license stated or linked to above. A copy can be downloaded for personal non-commercial research or study, without prior permission or charge. This item cannot be reproduced or quoted extensively from without first obtaining permission in writing from the copyright holder(s). The content must not be changed in any way or sold commercially in any format or medium without the formal permission of the copyright holders. 


\section{Functionally graded adhesive joints - a review and prospects}

\section{J F Durodola*}

Department of Mechanical Engineering and Mathematical Sciences, Oxford Brookes University, Wheatley Campus, Wheatley, OX33 1HX

There is increasing demand for effective and efficient lightweight structures because of global environmental and resource sustainability concerns. Adhesive bonding has been adopted in many assembly arrangements because of its relative reduction of stress concentration in joints compared to mechanical fasteners. Functionally graded bonded joints presents even greater potentials for reduction of stress concentrations and the tailoring of stress distribution as may be desired in an adhesive layer. This capability provides opportunity for the design of high performance tailored structural assemblies. Although some encouraging analysis and experimental work have been carried out on the development of functionally graded joints, its wide application is still to be realised. This paper reviews the work that has been carried out so far on the method, in terms of analysis, fabrication, experimental testing and application. It also reflects on outstanding issues that need to be resolved in order for wider application to be feasible.

Keywords: Functionally graded adhesive (FGA) joint, functionally graded materials, bonded joints, joint design and optimisation, bi-adhesive, optimisation,

${ }^{*}$ Correspondence author. Tel.: 44-1865-483-501; E-mail address: jdurodola@brookes.ac.uk (J.F.Durodola) 


\subsection{Introduction}

The interest in functionally graded adhesive (FGA) joints appeared to have started in 1961 during a development project for bonded rocket motor cases. The project was carried out by Republic Aviation Corporation in Farningdale in USA. The findings of the project were reported in publications in 1966 [1, 2] , and later in 1970 [3]. Further resurgence of interest in the area started again in early 2000s. This rekindled interest appears to have coincided with new initiatives in the exploration of general applications of functionally graded materials (FGM) especially in Japan. Koizumi in [4] and [5] suggest that the concept of Functionally graded materials was proposed in 1984 as a way to produce thermal barrier coating materials as part of developments for space plane production. Interest in FGMs in Europe initially also focussed on protection of lightweight aerospace structures from surface temperatures of up to $1850^{\circ} \mathrm{C}$ and temperature difference of $1600^{\circ} \mathrm{C}$ [6]. It should however be noted that FGM have always existed in natural materials, the microstructures of materials such as the stem of bamboo, corn, barley [7], bone and teeth [8, 9] show this clearly. The mid to late 1990s saw special journal issues on FGMs in journal. Composites Engineering now Composite Part B had special issues in 1995 and 1997, Materials Research Bulletin published a special issue on FGM in 1995. Some exploratory studies of the method for aero engine applications were carried out in the late 1990s and early 2000s [10-12]. A cursory search for articles on the material now yields about 350,000. The pervasive interest in FGMs has led to thoughts of its application in adhesive bonded joints. The potential benefit of FGA joints in improving joint strength has been explored analytically and experimentally. The paper reviews these works with a view to identifying progress and ultimately suggesting areas of further prospect for analysis and fabrication of FGA joints that will lead to wider application.

\subsection{Background}

It is helpful to first highlight the stress and strain state in a typical adhesively bonded joint such as the lap joint in order to provide the basis and motivation for functionally graded adhesive (FGA) joints. Figure 1 shows an illustrative lap joint with applied load $P$, overlap length $L$, adherend thickness and width $t$ and $w$ respectively and adhesive thickness $d$. Single lap joints are by far the most widely used adhesive joints and have been the subject of considerable research. The loads in a single lap joint are not co-linear, a bending moment therefore exists which causes the joint to rotate. This loading configuration consequently exposes the adhesive layer to shear, and peeling stresses at the ends of the joint identified as points $e$ in Figure 1(b). Studies have shown that the strain distribution along the length of the joint is not uniform; the stress is distribution is also consequently not uniform. Both shear and peel stresses are found to peak towards the outside surface at points $e$. Early theoretical work by Volkersen showed that the strength of the non uniformity of these fields depend on the difference in the mechanical properties of the adhesive and the adherend [13]. The mismatch in the mechanical properties of the adhesive and the adherends has been shown through theoretical calculations to lead to stress intensity at the free edge. A state of uniform strain and stress distribution means more uniform load transfer and consequently higher joint strength. It is therefore desirable to have uniform stress distribution in joints. 


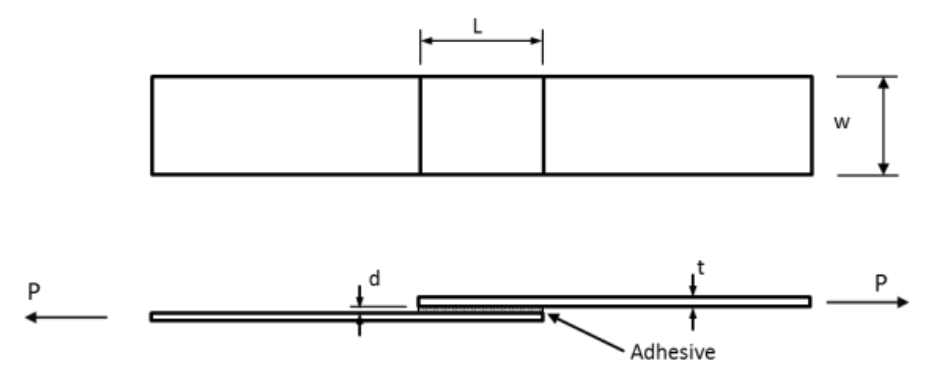

(a)

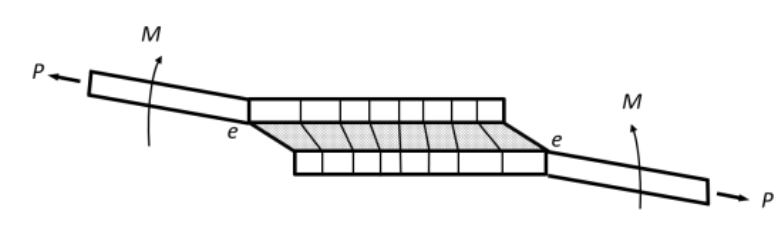

(b)

Figure 1. Simple lap joint (a) configuration (b) illustration of cause of strain concentration and hence stress concentration at the ends.

As highlighted above, the stress distribution within a joint varies with the adhesive and adherend properties, and with the overall geometry. Softer adhesives tend to generate more uniform stress distribution. However, even when softer adhesives are employed, the load is never uniformly distributed and the stress state is complex. The use of geometry to modify the strain and stress states in a bond line has long been known, see for example [3]. Some of the methods include bevelling of lap ends, material cut outs at ends of laps, bending of lap ends, internal bevelling, reverse bent and wave joints $[3,14]$. As highlighted in the foregoing, the general interest in FGMs has encouraged the efforts that have been made over last two decades to use FGM methods in adhesive bond lines. A lot of effort has been made in various areas of application of bonded joints to use analysis to predict the potential benefits that can be gained by using FGM. Efforts have also been made to assess the use of FGM in ameliorating process induced problems such as residual stresses. Effort is made in what follows to review a broad cross section of research that has been published on FGA joints.

\subsection{FGA joint analysis and design}

\subsection{Founding theoretical basis and further developments}

The initial work reported on optimisation of a functionally graded adhesive joint is a convenient introduction to the main issues involved in the analysis and design of a graded bond joint. Raphael [1] used plate bending analysis to derive equations (1) and (2) which is a set of coupled governing differential equations for shear stress and normal stress variations in a lap joint bent into cylindrical shape.

$$
\frac{1}{G} \frac{d^{3} \tau}{d x^{3}}+\phi_{1} \frac{d^{2} \tau}{d x^{2}}+\left(\phi_{2}-\eta_{1}\right) \frac{d \tau}{d x}+\phi_{3}=\eta_{2} \sigma
$$




$$
\frac{1}{E} \frac{d^{4} \sigma}{d x^{4}}+\psi_{1} \frac{d^{3} \sigma}{d x^{3}}+\psi_{2} \frac{d^{2} \sigma}{d x^{2}}+\psi_{3} \frac{d \sigma}{d x}+\left(\psi_{4}+\frac{1}{t D_{L}}+\frac{1}{t D_{u}}\right) \sigma=\eta_{3} \frac{d \tau}{d x}
$$

where $G$ is shear modulus, $\sigma, \tau$ are normal and shear stress respectively, $\phi$ and $\psi$ are functions of adhesive $E$ and $G$ moduli respectively. The $\eta$ terms are functions of the adherend and joint geometry. The dimensions of the left and right adherends and widths are $D_{L}, D_{u}$ and $t$ respectively. In order to analyse a functionally graded joint with $n$ discrete adhesives, Raphael used the notation in Figure 2 to denote the location of the ends of the adhesives.

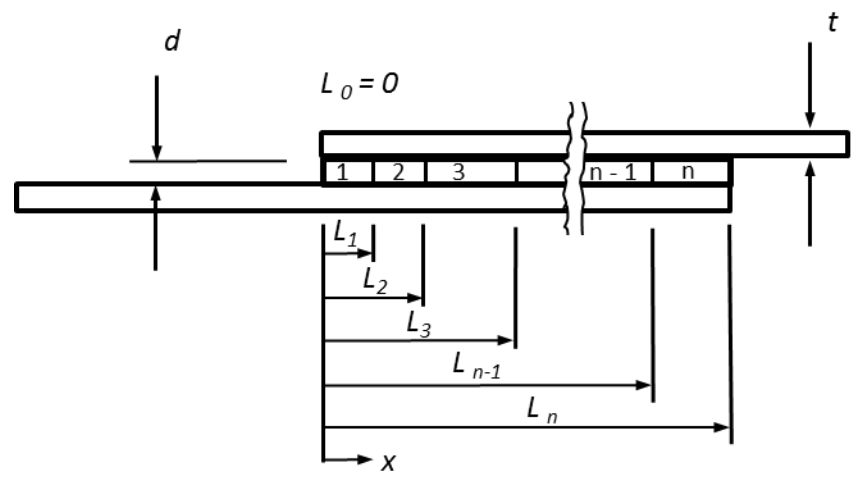

Figure 2 Model of discrete adhesive joint [1]

Each adhesive is defined by its length $L_{i}-L_{i-1}$ and shear modulus $G_{i}$. For the case of equal adherends the governing equations become uncoupled and reduces to the simpler form shown in equation (3) which has solution of the form given in equation (4).

$$
\begin{gathered}
\frac{d^{3} \tau_{i}}{d x^{3}}-\frac{8 G}{E T t} \frac{d \tau_{i}}{d x}=0 \\
\tau_{i}=a_{i}+b_{i} \cosh \left(\frac{8 G_{i}}{E t d}\right)^{1 / 2} x+c_{i} \sinh \left(\frac{8 G_{i}}{E t d}\right)^{1 / 2} x
\end{gathered}
$$

The $3 n$ unknown constants $a_{i}, b_{i}$ and $c_{i}$ are determined by enforcing equilibrium and strain compatibility conditions at the adhesive interfaces and the boundary values of load and moment $P$ and $M$ respectively. The use of this model for optimising a bondline will follow an inverse iterative approach of continuously changing adhesive properties until an objective such as the desired joint load level is achieved. A second model is a linear fourth order differential equation with variable coefficients for the optimisation of a simple lap FGA joint. The dependent variable in the equation is the shear strength at various locations along the bondline. Both adhesive and adherend geometries are assumed fixed. The shear modulus is assumed to be expressed as a function of shear strength of adhesive materials. This approach will provide a direct solution for the form of shear modulus required to achieve a specified load. This latter approach however requires prior determination of shear modulus $G$ as a function of shear strength $\tau_{u}$.

In 1975, Srinivas [15] developed a refined analysis of bonded joints which accounts for transverse shear deformation and transverse normal stress in order to obtain the stresses and displacements in the adherends and in the adhesive layer. The approach allowed for stepped adherends to be 
analysed. The formulation was based on the use of polynomials to express variation of displacement in the thickness direction while the coefficients varied in the axial direction. The governing differential equations were obtained by integrating the equations of equilibrium. These were solved taking compatibility and boundary conditions into account. The results of the study showed that the maximum peel and shear stresses in the bond can be reduced by using a combination of flexible and stiff bonds. This is in agreement with the aims of the application of FGA. Sawa and Uchida [16] in 1997 carried out analytical stress analysis on band adhesive butt joints to determine the stress distribution. Experimental photoelasticity analysis was also carried out to verify the results. The effect of gaps in the adhesive bands and the ratio of modulus of the adhesive and adherends on stress distribution were carried out. Although the work did not use multimaterial in the joint, the gaps in the joints caused stress modification which is one of the primary purposes for using FGA joints.

da Silva et al carried out an extensive review of analytical models of adhesively bonded joints for both mono and mixed adhesive joints up to year 2009. The review highlighted the conditions of applicability and the stress components considered. They also considered how well the prediction of the models for strength of joints compared with experimental results $[17,18]$. There have been further developments on the development of theoretical solutions for FGA joints. In the last decade, Kumar and collaborators [19-22] studied tubular adhesive bonded joints subjected to axial loading. Analytical axisymmetric formulation was used. Smooth variation in modulus was used to show the modifications of the stress field. In reference [23] a shear lag model was proposed for the modelling of functionally graded adhesive anchors. The shear strain and stress were assumed to be proportionally related to the axial deformation of the embedded anchor. The shear modulus was taken to vary according to a power law. The governing differential equation was obtained by using the minimisation of the total energy functional. Power series solution approach together with various bonding boundary conditions were used to solve the governing equation. Solutions for the various bonding cases were given for linear variation of the shear modulus along the length of the anchor. The results of stress distributions obtained agreed well with FEM analysis results. Stein et al [24] extended Goland and Reisnner's model [25] for application to functionally graded adhesive lap joints. In order to account for the variation in adhesive modulus along the bond length, the governing differential equations were formed in terms of displacements rather than stresses. The formulation was based on Euler-Bernoulli beam theory which neglects the shear deformation of the adherends. In a similar work, Stein [26] developed a solution for FGA joints that could be used for various geometries such as lap, $\mathrm{L}$ - joint, $\mathrm{T}$ - joint, reinforcement patch and corner joints. The adhrerends could be sandwich composites and the formulation was based on the First Order Shear Deformation Theory (FSTD) [27]. The formulation admits Taylor series expansion of the adhesive modulus in powers of the coordinate along the length of the joint. The results showed good agreement with corresponding FEM models for the different orders of modulus variation considered. Wang and colleagues presented a different development on the Goland and Reisnner's model by developing a 3 - parameter elastic foundation solution for adhesively bonded joint [28]. This model in comparison to the Goland and Reissner's two parameter elastic foundation model is more complete and allows for all 8 feasible external forces and boundary conditions to be implementable. The 3 parameter model was extended to the solution of lap joints with functionally graded adherends. The model was validated through its agreement with FEM for different ratios of adherend to adhesive modulus ratios ranging from 20 to 70 . 


\subsection{FEM parametric approaches}

Sancarta and Kumar [29] were one of the earliest researchers to use FEM to model FGA joint. Selective rubber toughening approach was used to model different configurations of toughened and untoughened parts of the adhesive bond. The properties used were obtained from tests on representative bulk material. Linear and non-linear analysis were carried out. Although the paper did not refer to the FGM concept, the work applied FGM methods giving modelling and experimental results. Pires and others [30] applied a reduced form of FGA joint by using two adhesives in a bondline. A compliant, DP490, 3M adhesive was used at the ends of a lap joint and a stiffer ESP110 adhesive was used at the inner parts. Other speculative adhesive properties to generate different property and length ratios were also considered. The analysis was based on FEM using linear and non-linear material constitutive behaviours. The stress distributions obtained for the elastic analysis matched the shape that was theoretically predicted by Raphael ([1]. Figure 3 shows an illustration of the bi-adhesive lap joint used and the shape of the shear distribution obtained at the middle of the bondline for length ratio $L_{1} / L_{2}=0.5$ and for applied load $P=52 \mathrm{~N} / \mathrm{mm}$. Aluminium alloy adherend material was considered in the study.

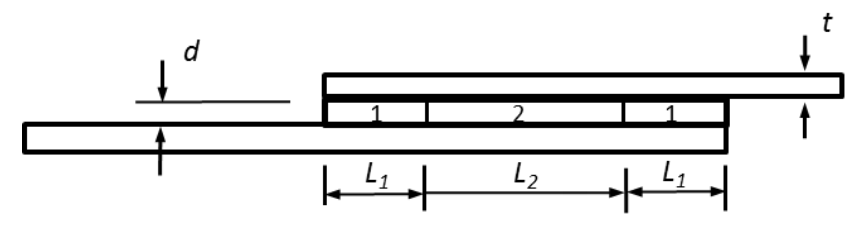

(a)

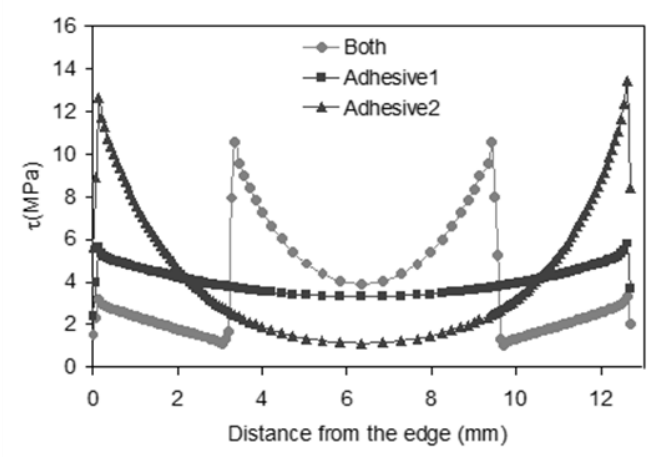

(b)

Figure 3 Illustration of bi-adhesive lap geometry (a) and the shear stress distribution obtained at the adhesive mid layer for $P=52 \mathrm{~N} / \mathrm{mm}$ and $\mathrm{L}_{1} / \mathrm{L}_{2}=0.5$

Kumar and Pandey [31] studied similar adhesive and adherend combinations using 2 and 3-D linear and nonlinear FEM. Similar results were obtained as in Pires et al. Effort was also made in their work to predict the stiffness of the joints. Another piece of work in 2003 graded the properties of the 
adherend by continuously varying the braid angle in a composite material [32]. Finite element analysis was used to compare the results obtained with that based on changing the geometry of the adherend. The work concluded that property gradation leads to more reduction in shear stress in a lap joint than changing the geometry of the adherend. Fitton and Broughton [33, 34] carried out studies on bi-adhesive graded joints but focussed primarily on composite adherend materials. Part of the study also considered bonding of dissimilar materials. FEM approach was used for the stress analysis. Improvements in joint strength was also predicted. In the latter work a review of various stress reduction methods at stress concentrations was carried out. Conclusions highlighted benefits of FGM especially in the bonding of dissimilar adherends. Experimental and FEM modelling analysis work was carried out by Marques and da Silva [35] which showed that dual adhesive bonded patches may be preferable to stiff adhesive bonded patches. This combination provides a more flexible and ductile response than a stiff adhesive bonded patch. This characteristic was said to be better for applications with dynamic loading. As in other studies the use of bi adhesive joint in double strap joints subjected to bending load showed higher strength performance than similar joints with mono adhesive[36].

da Silva and Adams [37] used FEM to study the potential gains that can be made by using a combination of low and high temperature adhesives to improve joint performance is applications such as space planes where joints can experience temperatures ranging from -55 to $232^{\circ} \mathrm{C}$. They concluded that strength gains were possible for cases of bonding of dissimilar adherends with combination of low and high temperature adhesives. The use of low and high temperature adhesives did not show improvement in the case of bonding similar adherends. Ozer and $\mathrm{Oz}$ [38] carried out three dimensional FE analysis of a double lap joint bi-adhesive joints. Contact elements were used between adhesive and adherend surfaces. As with other geometries, the edge stresses were reduced with the use of compliant adhesive at the edge and stiffer in the middle parts of the bond length. They also concluded as in other studies that bond length ratios can be used to optimise a bond system for strength. Vallee et al [39] studied the effects of various stress reduction methods on the strength of joints with orthotropic brittle adherends. The methods considered included adhesive rounding, chamfering and adhesive grading. The brittle materials considered were fibre reinforced polymer composites and timber. They observed that FEA showed that all of the methods lead to shear and peel stress reduction at the joints. They however also observed that experimental testing did not show any of the methods to yield improvement in strength of FRP or timber joints. Instead of using stresses directly as failure criterion, the authors suggested from their work that a Weibull based statistical approach based on $50 / 50 \%$ chance of survival or failure gives better prediction.

\subsection{Adhesive bonding of functionally graded materials and functionally layered bond lines}

The work reported in the foregoing used functionally graded adhesive bondline. Some related work have however considered mono adhesives that are bonded to functionally graded materials. Some work have considered layered bondline between two dissimilar materials. Apalak and Gunes [40] carried out similar work to Boss et al. In this case however, an adhesive layer was used to bond alumina $\mathrm{Al}_{2} \mathrm{O}_{3}$ to pure nickel in simple lap. Three - dimensional FEM was used to analyse the effect of the exponent in the power law used to describe the graded composition of the adherends on the normal and shear stress variation in the materials including the adhesive. The variations observed show that grading the material composition exponent can be used to influence the stress in the adhesive layer. Similar procedures were followed in the analysis of functionally graded tubular 
single lap joint in tension [41]. The material system was the same as in the earlier work. Similar increase in the shear stress in adhesive was obtained the ceramic material power law exponent was increased as in the case simple lap joint. Temiz [36] carried out analysis of the effect of use of a biadhesive compared to mono adhesive on double strap joints subjected to external bending load. As in other types of joints, the stress concentration at the end of joints were reduced by using compliant adhesive there and stiffer adhesive internally. More of the load transfer was transferred to the inner layers hence increasing joint strength. Apalak and his group of researchers carried out computation modelling on functionally graded materials in single lap and tubular single lap configurations to determine the effects of ceramic content on natural frequency, modal shape, and flexural deformation and induced thermal residual stresses [42-47]. In all these studies, the impact or the level of the stress in adhesive is rises as the stiffness of the adjoining adherent rises. Similar to Apalak's groups work, there were analysis work for the modification of stresses in coated plates using graded interlayer bonding [48], based on plate bending analysis. Stapleton ([49] modelled functionally layered joints by using a combination of Euler-Bernoulli beam theory, plate bending and classical laminate theory method. Up to $45 \%$ reduction in peel stress were predicted compared to use of stiff adhesive.

\subsection{Joint design and optimisation}

Although Raphael's founding work [1] presented governing equations that could be used for the optimisation of functionally graded joint design, most subsequent analysis reported have been based on parametric studies. These were used to reflect the effect that changes to joint geometry and relative stiffnesses of the adhesive and adherend materials have on the modification of stress distribution functionally graded joints. The ideal application of FGM bond layer should be based on an optimised design. For the case of symmetric joint, Raphael gave the homogeneous form of equation (1) as shown in equation (5) as the differential equation that can be solved using optimisation methods to obtain a required shear modulus distribution. The equation could be solved subject to desirable boundary conditions such as described in equations (6) and (7)

$$
\begin{gathered}
\frac{1}{G} \frac{d^{3} \tau}{d x^{3}}+\phi_{1} \frac{d^{2} \tau}{d x^{2}}+\left(\phi_{2}-\eta_{1}\right) \frac{d \tau}{d x}+\phi_{3}=0 \\
\tau(0)=\tau(L)=\bar{\tau} \\
P=\int_{0}^{L} \tau d x
\end{gathered}
$$

where $\bar{\tau}$ is a desired allowable shear stress.

Some researchers have included optimisation consideration in the FGA joint analysis. Breto and colleagues $[50,51]$ studied single lap joint subject to tensile loading. Five parameters were used to define property gradation along the length of the joint. Factorial studies was carried out in order to determine the parameters that optimised the strength of the joint. In the vibration analysis, optimisation work was carried out using artificial neural network and genetic algorithm [45]. The objectives were maximisation of natural frequency and minimisation of strain energy. The studies considered first mode of vibration. Among the optimisation parameters were plate length, thickness, and adhesive thickness. Spaggiari and Dragoni [52] presented an axisymmetric formulation for the 
analysis of functionally graded tubular lap joint subjected to torsional loading. The objective in the optimisation formulation was constant shear stress in the adhesive layer. The stiffness distribution which gives this stress state is expressed as a function of the elastic and geometric parameters of the joint.

\subsection{Manufacturing and experimental testing}

Manufacturing remains one of the major issues in applying the FGA technology. The primary aim of this section is to describe the manufacturing methods used by various researchers. As highlighted in the introduction, functionally graded adhesive joints offer remarkable potentials for stress redistribution and reduction and hence improve structural performance. Virtually all published papers show through analysis or modelling that significant reduction in peak stresses can be achieved. This observation and deduction has been confirmed by experimental testing. Semerdjiev [3] indicated that tests have shown that lap joint strengths can be increased by using a bi-layer adhesive joint in which flexible adhesive carries the strain at the ends and a brittle adhesive used at the centre. As highlighted in the foregoing, Sancarta and Kumar [29] were one of the earliest researchers to use the FGM concept although not identified as such at the time. Toughened rubber epoxy was placed at the ends of the joints where stress concentration and intensity occurs. The toughened epoxy was made by a combination of epoxy, adduct and a hardener. The adduct was made mixing $40 \%$ by weight carboxyl terminated acrylonitrile butadiene rubber and $60 \%$ by weight Epon 830 epoxy resin $120^{\circ} \mathrm{C}$ for $1.5 \mathrm{hrs}$. Ancamin, an aliphatic amine was used for the hardening. In order to obtain 0,10 and 20 parts per hundred rubber toughened epoxy the following combinations of epoxy, adduct and a hardener were used: $100 \mathrm{~g} / 0 \mathrm{~g} / 60 \mathrm{~g}, 85 \mathrm{~g} / 25 \mathrm{~g} / 60 \mathrm{~g}$ and $70 \mathrm{~g} / 50 \mathrm{~g} / 60 \mathrm{~g}$ respectively. The adherend used was AISI 1080 cold rolled steel with 3.175 and $12.7 \mathrm{~mm}$ thickness and width respectively. Two overlap lengths of 12.7 and $25.4 \mathrm{~mm}$ were considered respectively. The adhesive thickness was $0.2 \mathrm{~mm}$ and the curing was carried out at $60^{\circ} \mathrm{C}$ for 2 hours followed by $100^{\circ} \mathrm{C}$ for 1 hour. Various bonding schemes were used in the study. Some of these included use of $6.35 \mathrm{~mm}$ toughened rubber ends with untoughened adhesive in the middle and no adhesive in the middle part as well as use of toughened and untoughened adhesive in the full bond layer. Tensile tests carried out showed that selectively toughening the ends of joints gave similar strength as using toughened adhesive all through the bond length. This strength was however significantly higher than that obtained from test on the toughened brittle adhesive.

Pires et al [30] performed tests on a bi-layer adhesive lap joint with a view to verify possible improvements suggested by the modelling work. No special adhesive formulations were considered in the study. Two epoxy adhesives were simply chosen for the study. DP490 produced and ESP110 both produced by Permabond were used. DP490 is a compliant adhesive with Young's modulus, E, of 1.8 GPa while ESP110 is about three times as stiff with $\mathrm{E}=5.9 \mathrm{GPa}$. This choice provides a desired wide difference in stiffnesses. The DP490 is a two-part epoxy which can be cured at room temperature for 24 hours followed by 1 -h exposure at $80^{\circ} \mathrm{C}$. It is a relatively compliant adhesive. The ESP110 is a one-part adhesive, which can be cured at $150^{\circ} \mathrm{C}$ for $30 \mathrm{~min}$. It is relatively stiff but not brittle. An AA 2024 T3 aluminium alloy adherend with $1.6 \mathrm{~mm}$ thickness and was used. The overlap length in the experiments carried out was $14 \mathrm{~mm}$. The ratios of the edge adhesive to middle adhesive length $L_{1} / L_{2}$ was approximately $0.33,0.70$ and 1.8 respectively. These were determined by taking measurements after joint test to failure. Adhesive mixing during fabrication led to these ratios instead of the originally intended ratios of $0.2,0.7$ and 2.0 respectively. For the joints with the biadhesive bondline, the adhesives were applied in two stages. In the first stage, teflon tapes of length L1; Fig3 1, were put on the ends of the overlap length of one adherend and the ESP110 adhesive was applied to the middle part of length L2: In the second stage, the tapes were removed and the DP490 
adhesive was put on the lengths L1 at the ends of the overlap length. The second adherend was then applied and the joint cured. The curing cycle was adapted in order to optimise the strength of the joint. A compromise between the curing cycles of the two adhesives was found, after several tests to be maintenance at $120^{\circ} \mathrm{C}$ in the oven for a duration of 1 hour and $20 \mathrm{~min}$. The material properties used in the numerical analysis of the single and the bi-adhesive joints were subsequently obtained from dumb-bell specimens produced using the common cure conditions. The improvement obtained in five repeats of tensile testing on lap shear joints and averaging showed about $22 \%$ increase in strength compared to those of mono adhesive lap joints.

Fitton and Broughton [33] carried out a bi-adhesive experimental work using a high modulus adhesive with Young's modulus $E=2.4-2.8 \mathrm{GPa}$ and a low modulus adhesive with $E=0.37 \mathrm{GPa}$. Two CFRP and one steel adherends were considered. The overlap length in the lap joint tests was 50 $\mathrm{mm}$ and the adhesive thickness was $0.25 \mathrm{~mm}$. The adhesives were physically laid end to end by hand. The adhesives used were two part ambient cured epoxies and had similar ambient cure characteristics. Five replicate tensile tests were carried out on the bi-adhesive joints. The manufacturing work by Vallee et al [39] used SikaDur330, SikaForce7851 and SikaFast5221 adhesives which are stiff, medium level of plasticity and major plastic deformation respectively. The adherends considered were E-glass fibre in polyester resin FRP and timber. For the FGA joint work, adhesive grading was achieved by using SikaDur330 in the centre of the splice joint and SikaForce7851 for the ends of the overlap for FRP adherend. SikaFast5221 was used at the ends in the case of timber adherends. As in the work by Pires et al, no physical separation was imposed between the adhesives. There was therefore a risk of mixture. All joints were however examined after tests to determine the real level of gradation achieved. Overlap length and adhesive thickness considered were $100 \mathrm{~mm}$ and $1 \mathrm{~mm}$ respectively. The width of the joints considered were 35 and 50 $\mathrm{mm}$. No explicit curing strategies were reported. In the work by Stapleton et al [49], AF 163-27k adhesive [53] was stiffened by sprinkling glass beads with different densities in the central part of the strap joint. The ends were left free of the glass beads in the graded joint. The adherend was a composite with $52 \%$ triaxially braided fibre in Epon 862 epoxy resin matrix. The adherend was cured prior to bonding. The bonded joint was cured by a heated press at $177^{\circ} \mathrm{C}$ under $0.43 \mathrm{MPa}$ for 2 hours. The specimens were not handled for $24 \mathrm{~h}$ before testing.

The experimental work by da Silva and Adams[54] considered titanium/titanium and titanium/ adherends in double lap joint. The of using FGA joint was to cater for high performance at both low $50^{\circ} \mathrm{C}$ and high $200^{\circ} \mathrm{C}$ operating conditions. Redux 326 (Hexcel Composite) and Supreme 10HT (Master Bond) adhesives were selected to cater for high temperature and low temperature load carrying capabilities. In order to guarantee that the two adhesives did not mix during fabrication, $1 \mathrm{~mm}$ by $5 \mathrm{~mm}$ pre cured silicone rubber was used to separate the two adhesives. They avoided the use of a metallic strip to remove the possibility of the interface becoming a crack like defect in the bondline. The curing protocol for Redux 326 is $175^{\circ} \mathrm{C}$ for 2 hours and a post cure at $230^{\circ} \mathrm{C}$ for $2 \mathrm{~h}$. The Supreme $10 \mathrm{HT}$ adhesive however required $120^{\circ} \mathrm{C}$ for $1 \mathrm{~h}$. They opted for the Redux 326 cure process requirements because this required higher curing temperature and the joint application is high. They however carried out separate tests to ensure that the Supreme 10HT properties were not aced by other researchers [30,33,39]. In a subsequent work, by Marques and da Silva, for damage patch repair[35], Araldite AV138/HV998 and Araldite 2015 adhesives and A6063 T6 aluminium alloy adherend were used. In this work nylon strip was used instead of silicone rubber. They were able with nylon to use smaller separation area between the adhesives compared to the case with use of silicone as the separator.

The manufacturing method used by Carbas et al [55] appears to be the most advanced in terms of development to date. The adhesives considered were Araldite 2011 (Huntsman, Basel, Switzerland) and Loctite Hysol 3422 (Henkel, Dublin, Ireland). The properties of the adhesives were previously 
characterised as a function of cure temperature $[56,57]$. The adherend was high strength steel (DIN C65 heat treated). Single lap joints with 1,2, and $50 \mathrm{~mm}$, adhesive and adherend thickness and overlap length respectively were considered. The FGA joint study used induction heating graded cure method. A mould was made to accommodate the specimen and the induction coil required for the graded cure of the joint. Induction heating was carried out at the ends and induction cooling in the middle of the joint to achieve the graded cure. The method provides significant opportunity for controlling gradation of property which is excellent for optimisation tuning purposes.

Kawasaki et al [58] proposed a simpler way of achieving FGA layer by using two part stiff and compliant adhesive materials. They used a multiaxis (SHOTMASTER DS SM200DSZ, Musashi Engineering Co. Ltd, Japan) robot to dispense the adhesives on the adherends. The oxidiser from the two adhesives are dispensed in a required graded ratio on one adhesive and the reducer from the adhesives similarly dispensed in the same ratio on the second adherend. The two adherends are then bonded by the fast honeymoon adhesion process. The two adhesives used were of second generation two part acrylic type [58]. It is conceivable that the use of the robot allowed precision deposition of the adhesives and the fast honeymoon process supported the maintenance of the ratios during bonding and curing. Kumar et al [59] have used the advancement in $3-\mathrm{D}$ printing technology to produce FGA joints. Object Connex260 Polyjet 3D multimaterial printer was used for the fabrication process. The printer had eight printing heads that sprays liquid polymer materials used. The materials were photopolymers that are cured by exposure to UV light. The adherends were VeroWhitePlus RGD835 (VW) with Young's modulus of $2.25 \mathrm{GPa}$ and the adhesives were TangoPlus FLX930 (TP) and a digital material S40 having Young's moduli of ).536 MPa and $1.098 \mathrm{MPa}$ respectively. About 100 and $150 \%$ increase in strength and toughness were obtained for the centre stiffness and edge compliant tailored adhesive joints compared to the nontailored constant modulus joints.

\subsection{Challenges}

Some challenges have been noted against the use of FGA joints. The primary challenge relates to manufacturing. A number of considerations are involved in the manufacture of adhesive joints for sustainable performance. In broad terms this includes selection of the right adhesive for the adherends to be bonded for an application and environment, determination of optimal joint dimensions, surface preparation, jigging to ensure all parts remain in desired position during manufacture, right curing conditions and others. One of the early manufacturing issue that was raised particularly for bi-adhesive joints was that the middle stiffer adhesive could squeeze out the compliant adhesive at the end of joints $[37,60,61]$. There was a view that the gains from functional grading will not be sufficient to justify production difficulties [49,60,61]. Concerns have also been raised that optimised FGM may be sensitive to circumstances such as unintended changes in the loading, dimensions and direction [49]. Broughton and Fitton [34] highlighted the difficulty of identifying a common surface pre-treatment that is suitable for the adherends and the adhesives to be used in a graded joint. Other concerns include the challenges of controlling the deposition of the adhesive to match the optimised requirements in general not only for bi-adhesive case, identification of appropriate curing process. This latter aspect was commented on by virtually all researchers who carried experimental testing especially in references [30, 33, 54]. Other notable temporal challenge is the general reluctance of industry to shift to new methodology because of development and certification costs. 


\subsection{Prospects}

In this section we reinforce the benefits that can be gained for the use of FGA joints as well as areas of development that need attention. It should be noted that all numerical and analytical work reported so far indicate that end shear and peel stresses in joints are significantly reduced by using a functionally graded adhesive bondline. Joint strength is maximised when appropriate or optimised graded bond line property is used. The method has been shown from modelling to have significant potentials for reduction of residual stresses and increase in natural frequency of vibration in some assemblies. The method also shows that functionally graded bondline enhances the integrity of joints that experience highly varying temperature conditions such as very low $\left(-55^{\circ} \mathrm{C}\right.$ to very high $230^{\circ} \mathrm{C}$ ). Virtually all experimental work reported have also shown improvement in joint strength by 20 to $45 \%$ in some cases. Only in one experimental case was the gain in strength due to functionally graded bondline was deem to be insignificant [39]. A gain in strength is undoubtedly helpful towards realising sustainability requirements in terms of light weighting for efficient performance and consequently reduction of environmental pollution. It should also be noted that there is usually correlation between static strength and fatigue strength. The increase in number of cycles to failure can increase by more than an order of magnitude even for as low increase in strength as $10 \%$. The prospects of the application of the method can be enhanced by addressing the challenges highlighted in the foregoing. Further attention is needed in the following areas:

- Development of readily applicable optimisation methods for the design of functionally graded bonded joints rather than parametric studies is still a challenge that has not received sufficient attention. Optimisation methods will permit the use of desired objectives directly in solving FGA joint problems.

- Development of methods for the controlled dispensing of multi-adhesive with rather limited or no mixing. This initiative can benefit from latest precise printing technology. Adhesive mixing can be avoided by leaving appropriately determined gaps between dispense adhesive. Computation fluid dynamics can be used to study flow patterns to determine limits. This can then be validated by experimental testing. Although some progress was made by using silicone rubber and nylon separators [35, 37] more attention to this issue will be helpful. Further progress on the use of robot dispensing and 3D printing have started to appear $[58,59]$.

- Statistically based sensitivity analysis can be carried out to show the influence of realistic variabilities in the joint parameters. Some studies have been carried out on single adhesive bond layers [62] in which it was noted that peel stresses were more sensitive to changes in modulus than shear stress.

- There is need to continue to search for new curing methodologies that will lead to desired property gradation. This will require a fresh consideration of new and existing methods such as direct heat, electric heaters, infra-red radiation, induction heating, high frequency dielectric heating, low voltage electric heating and ultrasonic activation curing methods. The work by Carbas et al $[55,57,63]$ deserves particular mention as an encouraging pointer to what can be achieved in terms of property gradation through the use of an adaptable curing process.

- Development of multi adhesive and adherend compatibility studies suitable for the analysis of functionally graded adhesive joints. 
- While static gains in strength has been studied, the possible gains in structural integrity and reliability under dynamic loading has not received much attention. It is expected that remarkable gains in life under fluctuating loading would ensue.

\subsection{Conclusion}

This paper has reviewed a wide cross section of theoretical and experimental reported work on the use functionally graded adhesive bonding from the 1960s to date. The founding theoretical basis for FGA joints has been highlighted. All theoretical reported work show that strength of adhesive bonded joints can be significantly increased using an optimised graded bondline design. The geometries that have been mostly studied include lap joint, strap joint, double lap joint and tubular lap joints. The loading considered include tensile, bending and torsion. Some thermal and dynamic loading cases were covered. The optimisation schemes that have been used have been highlighted. The challenges against the application of the method and the remarkable prospects possible have been discussed.

\section{References}

1. Raphael, C., Variable-adhesive bonded joints. Applied polymer symposia, 1965(3): p. 99-108.

2. Hauck, J.E., Answers to five common adhesive problems. Materials in Design Engineering, 1966: p. 3.

3. Semerdjiev, S., Metal to metal adhesive bonding. 1970, London: Business Books Limited.

4. Koizumi, M. and M. Niino, Overview of FGM research in Japan. Materials Research Bulletin, 1995. January: p. 3.

5. Koizumi, M., FGM activities in Japan. Composites Part B, 1997. 28B: p. 4.

6. Kaysser, W.A. and B. Ilschner, FGM activities in Europe. Materials Research Bulletin, 1995. January: p. 22-26.

7. Amada, S., Hierarchical functionally gradient structures of bamboo, barley and corn. Materials Research Bulletin, 1995. January: p. 35-36.

8. Amada, S., Hierarchical functionally graded structures of bamboo, barley and corn. Materials Research Bulletin, 1995. January: p. 2.

9. Nogata, F. and H. Takahashi, Intelligent functionally graded material: bamboo. Composites Engineering, 1995. 5 (7): p. $743-752$.

10. Durodola, J.F. and O. Attia, Deformation and stresses in functionally graded rotating disks. Composites Science and Technology, 2000. 60 (7): p. 987-995.

11. Durodola, J.F. and O. Attia, Property gradation for modification of response of rotating MMC discs Materials science and technology, 2000. 16 (7-8): p. 919-924.

12. Durodola, J. and J. Adlington. Functionally graded material properties for disks and rotors. in Key Engineering Materials. 1997. Trans Tech Publ.

13. Volkersen, O., Rivet strength distribution in tensile-stressed rivet joints with constant crosssection. Luftfahrorschung, 1938. 15 p. 41 - 47.

14. Fessel, G., et al., Evaluation of different lap-shear joint geometries for automotive applications. International Journal of Adhesion and Adhesives, 2007. 27 p. 574-583.

15. Srinivas, S., Analysis of Bonded Joints. 1975, DTIC Document.

16. Sawa, T. and H. Uchida, A two dimensional stress analysis and strength evaluation of band butt joints subjected to tensile loads. Journal of Adhesion Science and Technology, 1997. 11(6): p. 811-833.

17. da Silva, L.F., et al., Analytical models of adhesively bonded joints-Part II: Comparative study. International Journal of Adhesion and Adhesives, 2009. 29(3): p. 331-341. 
18. da Silva, L.F., et al., Analytical models of adhesively bonded joints-Part I: Literature survey. International Journal of Adhesion and Adhesives, 2009. 29(3): p. 319-330.

19. Kumar, S., Analysis of tubular adhesive joints with a functionally modulus graded bondline subjected to axial loads. International Journal of Adhesion and Adhesives, 2009. 29(8): p. 785-795.

20. Kumar, S. and J.P. Scanlan, Stress Analysis of Shaft-Tube Bonded Joints Using a Variational Method. Journal of Adhesion, 2010. 86(4): p. 369-394.

21. Kumar, S. and J.P. Scanlan, On axisymmetric adhesive joints with graded interface stiffness. International Journal of Adhesion and Adhesives, 2013. 41: p. 57-72.

22. Kumarz, S., Modeling of cylindrical joints with a functionally graded adhesive interlayer. Advances in Modeling and Design of Adhesively Bonded Systems, 2013: p. 47-91.

23. Kumar, S. and M. Khan, A shear-lag model for functionally graded adhesive anchors. International Journal of Adhesion and Adhesives, 2016. 68: p. 317-325.

24. Stein, N., H. Mardani, and W. Becker, An efficient analysis model for functionally graded adhesive single lap joints. International Journal of Adhesion and Adhesives, 2016. 70: p. 117125.

25. Goland, M. and E. Reissner, The stresses in cemented joints. Journal of applied mechanics, 1944. 11(1): p. A17-A27.

26. Stein, N., P. Weißgraeber, and W. Becker, Stress solution for functionally graded adhesive joints. International Journal of Solids and Structures, 2016. 97: p. 300-311.

27. Liu, Z., et al., A general solution for the two-dimensional stress analysis of balanced and unbalanced adhesively bonded joints. International Journal of Adhesion \& Adhesives, 2014. 54: p. 112-123.

28. Wang, J. and C. Zhang, Three-parameter, elastic foundation model for analysis of adhesively bonded joints. International Journal of Adhesion and Adhesives, 2009. 29(5): p. 495-502.

29. Sancaktar, E. and S. Kumar, Selective use of rubber toughening to optimise lap joint strength Journal of Adhesion Science and Technology, 2000. 14(10).

30. Pires, I., et al., Performance of bi-adhesive bonded aluminium lap joints. International Journal of Adhesion and Adhesives, 2003. 23: p. 9.

31. Kumar, S. and P.C. Pandey, Behaviour of bi-adhesive joints. Journal of Adhesion Science and Technology, 2010. 24: p. 1251-1281.

32. Boss, J.N., V.K. Ganesh, and C.T. Lim, Modulus grading versus geometrical grading of composite adherends in single-lap bonded joints. Composite Structures, 2003. 62(1): p. 113121.

33. Fitton, M.D. and J.G. Broughton, Variable modulus adhesives: an approach to optimised joint performance. International Journal of Adhesion and Adhesives, 2005. 25: p. 329-336.

34. Broughton, J.G. and M.D. Fitton, Science of mixed adhesive joints, in Advanced Structural Material. 2011, Springer-Verlag. p. 257-281.

35. Marques, E.A.S. and L.F.M. da Silva, Joint strength optimisation of adhesively bonded patches. The Journal of Adhesion, 2008. 84(11): p. 915-934.

36. Temiz, S., Application of bi-adhesive in double-strap joints subjected to bending moment. Journal of Adhesion Science and Technology, 2006. 20(14): p. 1547-1560.

37. da Silva, L.F.M. and R.D. Adams, Joint strength predictions for adhesive joints to be used over a wide temperature range. International Journal of Adhesion and Adhesives, 2007. 27: p. 362-379.

38. Ozer, $\mathrm{H}$. and $\mathrm{O} . \mathrm{Oz}$, Three dimensional finite element analysis of bi-adhesively bonded double lap joint. International Journal of Adhesion and Adhesives, 2012. 37: p. 50-55.

39. Vallee, T., et al., Influence of stress-reduction methods on the strength of adhesively bonded joints composed of orthotropic brittle adherends. International Journal of Adhesion and Adhesives, 2010. 30: p. 583-594. 
40. Apalak, M.K. and R. Gunes, Investigation of elastic stresses in an adhesively bonded single lap joint with functionally graded adherends in tension. Composite Structures, 2005. 70(4): $p$. 444-467.

41. Apalak, M.K., Elastic stresses in an adhesively-bonded functionally-graded tubular single-lap joint in tension. Journal of Adhesion Science and Technology, 2006. 20(9): p. 1019-1046.

42. Gunes, R., M.K. Apalak, and M. Yildirim, The free vibration analysis and optimal design of an adhesively bonded functionally graded single lap joint. International Journal of Mechanical Sciences, 2007. 49(4): p. 479-499.

43. Apalak, M.K. and R. Gunes, The elastic flexural behaviour of an adhesively bonded single lap joint with functionally graded adherends. Materials \& Design, 2007. 28: p. 1597-1617.

44. Apalak, M.K., R. Gunes, and S. Eroglu, Thermal residual stresses in an adhesively bonded functionally graded tubular single lap joint. Journal of Adhesion Science and Technology, 2013. 27: p. 26-48.

45. Apalak, Z.G., et al., Free vibration analysis of an adhesively bonded functionally graded double containment cantilever joint. Journal of Adhesion Science and Technology, 2014. 28(12): p. 1117-1139.

46. Apalak, M.K. and M.D. Bagci, Thermal Residual Stresses in Adhesively Bonded In-plane Functionally Graded Clamped Plates Subjected to an Edge Heat Flux. Journal of Adhesion Science and Technology, 2011. 25(15): p. 1861-1908.

47. Gunes, R., et al., Free vibration analysis of adhesively bonded single lap joints with wide and narrow functionally graded plates. Composite Structures, 2010. 92(1): p. 1-17.

48. Kashtalyan, M., M. Menshykova, and I.A. Guz, Use of a functionally graded interlayer to improve bonding in coated plates. Journal of Adhesion Science and Technology, 2009. 23: p. 1591-1601.

49. Stapleton, S.E., A.M. Waas, and S.M. Arnold, Functionally graded adhesives for composite joints. International Journal of Adhesion and Adhesives, 2012. 35: p. 36-49.

50. Breto, R., et al., Functionally Graded Bond-Lines for Metal/Composite Joints, in ECCM16 16th European Conference on Composite Materials. 2014: Seville, Spain.

51. Breto, R., et al., Finite Element Analysis of Functionally Graded Bond-Lines for Metal/Composite Joints. Journal of Adhesion, 2015. 91(12): p. 920-936.

52. Spaggiari, A. and E. Dragoni, Regularization of torsional stresses in tubular lap bonded joints by means of functionally graded adhesives. International Journal of Adhesion and Adhesives, 2014. 53: p. 23-28.

53. 3M, AF 163-2 Technical Datasheet. 2009.

54. da Silva, L.F.M. and R.D. Adams, Adesive joints at high and low temperatures using similar and dissimilar adherends and dual adhesives. International Journal of Adhesion and Adhesives, 2007. 27: p. 216-226.

55. Carbas, R.J.C., L.F.M. da Silva, and G.W. Critchlow, Adhesively bonded functionally graded joints by induction heating. International Journal of Adhesion and Adhesives, 2014. 48: p. 110-118.

56. Carbas, R.J.C., L.F.M. da Silva, and G.W. Critchlow, Effect of post-cure on adhesively bonded functionally graded joints by induction heating. Proceedings of the Institution of Mechanical Engineers Part L-Journal of Materials-Design and Applications, 2015. 229(5): p. 419-430.

57. Carbas, R.J.C., et al., Effect of post-cure on the glass transition temperature and mechanical properties of epoxy adhesives. Journal of Adhesion Science and Technology, 2013. 27(23): p. 2542-2557.

58. Kawasaki, S., et al., Functionally graded adhesive joints bonded by honeymoon adhesion using two types of second generation acrylic adhesives of two components. The Journal of Adhesion, 2016. 92(7-9): p. 517-534. 
59. Kumar, S., B.L. Wardle, and M.F. Arif, Strength and Performance Enhancement of Bonded Joints by Spatial Tailoring of Adhesive Compliance via 3D Printing. ACS Applied Materials \& Interfaces, 2016.

60. Hart-Smith, L.J., Adhesive-bonded double-lap joints - NASA CR-112235. 1973.

61. Hart-Smith, L.J., Analysis and design of advanced composite bonded joints - NASA-CR-2218 1974.

62. Bhat, M., Probabilistic stress variation studies on composite single lap joint using Monte Carlo simulation. Composite Structures, 2015. 121: p. 351-361.

63. Carbas, R.J.C., et al., Effect of Cure Temperature on the Glass Transition Temperature and Mechanical Properties of Epoxy Adhesives. Journal of Adhesion, 2014. 90(1): p. 104-119. 